\title{
INTRODUCCIÓN DE TOMÁS DE AQUINO Y DEL MAESTRO SALMANTINO PEDRO DE OSMA A SUS RESPECTIVOS COMENTARIOS A LA «ÉTICA A NICÓMACO»
}

\author{
Juan Acosta Rodríguez \\ Universidad de Salamanca
}

\section{RESUMEN}

El profesor de la Universidad de Salamanca Pedro de Osma (1424-1481) compuso un comentario a la «Ética a Nicómaco», adoptando la traducción latina de Leonardo Bruni («El Aretino») y menospreciando el texto empleado por Santo Tomás. Dado el respeto con que el propio Pedro de Osma cita la «Suma Teológica» y el «Comentario a las Sentencias», se trata de comprobar hasta qué punto ha tenido en cuenta también el comentario del Aquinate a la «Ética».

El cotejo de las introducciones redactadas por ambos autores a sus respectivos comentarios refleja una tal divergencia de estructura y de método, asi como de planteamiento y contenidos, que nos llevan a pensar en la independencia del maestro salmantino respecto del de Aquino.

Su introducción sobresale por el ejercicio de exégesis aplicado a los textos de Aristóteles;por la apertura al resto de las obras del Filósofo; por el planteamiento de aporías y la discusión de opiniones divergentes. Comparativamente el texto del Angélico se nos presenta como más conciso y dogmático, sin crispación dialéctica y con un cierto aire de elevación teórica.

Palabras clave: Moerbeke, Tomás de Aquino, Orden, Leonardo Bruni, Pedro de Osam, Ciencia civil.

\section{ABSTRACT}

The teacher of the University of Salamanca Pedro de Osma (1424-1481) wrote a comment on the Nichomachean Ethics, following the Latin Tanslation by Leonardo Bruni, («Aretinus») and despising the text used by St.Thomas.

Due to the respect with what Pedro de Osma himself quotes the «Theological Summa» and the «Comment on the Sentences», it is about to verify how far he has also taken on account the Aquinas' Comment on the «Ethics».

The comparison of the introductions written by both authors to their respective comments shows such a divergence, both on the structure and method as well as on the planning and contents, that they lead us to think of the independence of the Salmantinian respect to the Aquinas.

His introduction stands out for the exegetical exercise applied to the aristotelian texts; for the opening to the rest of the work by the Philosopher; for the planning of the difficulties and the discussion of different opinions.

Comparatively, the text of the Angelicus is offered to us more concise and dogmatic, without dialectical eagerness and with a certain touch of theoretical elevation.

Key words: Moerbeke, St. Thomas, Order, Leonardo Bruni, Pedro de Osma, civil science. 
Al leer el comentario de Pedro de Osma a la «Ética a Nicómaco» de Aristóteles, llama la atención la ausencia total de referencias al previamente compuesto por Tomás de Aquino, si exceptuamos un par de alusiones fugaces en el libro décimo, único en que aparecen también reiteradas citas de la «Suma teológica» y del «Comentario a las Sentencias», a propósito de la cuestión de la esencia de la felicidad. Y, ciertamente, no se debe ello a menosprecio del Aquinate, siendo así que las menciones referidas son traídas a colación para reforzar sus propias tesis, que cree en concordancia con el sentir del Doctor Angělico. Quizá la razón de ese silencio sobre el comentario de Tomás a la «Ética» haya que buscarla en la alergia que el maestro salmantino experimenta ante la traducción latina arreglada por Moerbeke y empleada por el Aquinate, siguiendo así la senda crítica y despectiva de su mentor renacentista Leonardo Bruni, «e1 Aretino»:

Decidí no hace mucho tiempo poner en latín los libros de la Ética de Aristóteles, no porque no hubiesen sido traducidos ya con anterioridad, sino porque habían sido traducidos de tal manera, que más bien parecían haberlos convertido en bárbaros que en latinos. Hay constancia del autor de esa traducción (sea quien sea, lo cierto es que perteneció a la orden de Predicadores) y es patente su desconocimiento tanto de las letras griegas como de las latinas, pues en muchos lugares entendió mal el griego, y tradujo al latín de modo tan pueril e inexperto, que resulta imposible no sentir vergüenza ajena ante tan supina y crasa tosquedad. ${ }^{1}$

Queda, no obstante, la curiosidad por saber si, aun sin nombrarlo ni aludirlo, el de Osma ha utilizado o no el comentario de Tomás. Es evidente que llegar a una conclusión cierta en un sentido u otro, requiere un cotejo pormenorizado de la estructura y contenido de ambos comentarios. Dada la imposibilidad de llevar a cabo una labor tan minuciosa en el reducido espacio de este artículo, me limitaré a ofrecer tan sólo una pequeña muestra, aunque eso sí, tan significativa como puede ser el cotejo de las introducciones elaboradas por ambos autores a sus respectivos comentarios.

\section{LA INTRODUCCIÓN DE SANTO TOMÁS}

Salta a la vista la diversidad de planteamiento y estructura que ofrecen ambos autores. EI profesor salmantino sigue el iter clásico de los comentaristas antiguos, incluido Boecio, maestro de los escolásticos: Titulo, género o índole de la obra, materia, fin, partes y encuadramiento en el organigrama o catálogo de las ciencias.

Santo Tomás, por su parte, entra directamente a situar la obra aristotélica en el cuadro del saber, y, al hacerlo, perfila indirectamente el objetivo que se persigue con su estudio y la materia específica sobre la que versa. Más en concreto, el planteamiento tomista, tan típico de su talante intelectual, remonta cual águila el vuelo desde el comienzo para ofrecer desde arriba una panorámica previa del conjunto e ir descendiendo luego por etapas hacia el suelo en busca del detalle par-

1 Traduzco del texto latino editado por Labajos Alonso, José, Pedro de_Osma.Comentario a la Etica de Aristóteles, Publicaciones Universidad Pontificia de Salamanca, 1996, p. 47. -En adelante citaré esta obra con las siglas JL, seguidas de la página respectiva. 
ticular. La óptica adoptada está determinada por la idea de «orden», pues «ordenar es lo característico del sabio», y «es propio de la razón conocer el orden», siendo «la sabiduría la máxima perfección de la razón».2

En efecto, aunque las potencias sensitivas conozcan de modo absoluto algunas cosas, conocer el orden de una cosa respecto de otra es exclusivo del intelecto o razón. Ahora bien, el orden es de dos tipos: I) El de las partes de un todo o de una multitud entre sí [...];2) El orden de las cosas hacia el fin. Este orden es más importante que el primero, pues como afirma el Filósofo en XI de la Metafísica, el orden de las partes de un ejército entre sí, está subordinado al orden del ejército entero respecto de su caudillo. ${ }^{3}$

Tras estas consideraciones preliminares que justifican el punto de vista adoptado, el Aquinate establece que el «orden» al que se enfrenta la razón es cuádruple:

1. Un orden que la razón no crea, sino que solamente considera, como el orden natural.

2. El orden que produce la razón en su propio acto, p.ej., al ordenar los conceptos los unos respecto de los otros, y los signos de los conceptos, dado que son voces significativas.

3. EI orden que produce la razón en los actos voluntarios.

4. El orden que produce la razón en las cosas externas y de las que ella misma es causa, como en un arca 0 en una casa.

En resumen, vemos que hay un orden que la razón no produce, sino que se limita a conocer, y otro que ella misma produce. A su vez, el orden producido por la propia razón es triple, según se refiera a su propio acto, al acto de otra potencia 0 a las cosas exteriores. Pues bien, al estudiar cada uno de estos órdenes surgen las diversas ciencias, como hábitos perfectivos de la razón:

1. Filosofía natural, que estudia el orden no producido por la razón (aquí, observa Sto.Tomás, hay que incluir la metafísica).

2. Filosofía racional, que estudia el orden de las partes de la oración y el de los principios, tanto entre sí como respecto de las conclusiones.

3. Filosofía moral, que estudia el orden de las acciones voluntarias.

4. Artes mecánicas, que estudian el orden que la razón produce en las cosas externas y que ella misma ha creado.

Dentro de este cuadro general del saber queda claro el cometido y la materia de la filosofía moral, que según Tomás es de lo que trata la «Ética a Nicómaco»:

Lo propio de la filosofía moral es estudiar las actividades humanas en su orden recíproco y respecto del fin. ${ }^{4}$

Y explica enseguida qué entiende por «operationes humanae». Se trata de aquellos actos que proceden de la voluntad del hombre según el orden de la razón, pues de lo contrario no estaríamos ante una actividad propiamente humana, sino «natural». Así, pues, y dicho de otro modo:

2 Cfr. S. Thomae Aquinatis, In decem libros Ethicorum Aristotelis ad Nicomachum expositio,cura et studio, Spiazzi, R.N., Marietti, 1964, L.I, lect. I, n .l. —En adelante me referiré a esta edición con las siglas ST, seguidas del número respectivo del comentario.

3 ST, 1. Cfr. Metaf. Lambda, 10, 1075a, pp. 11-15.

4 ST, 2. 
El objeto de la filosofía moral es la actividad humana ordenada al fin o, también, el hombre en cuanto que obra voluntariamente por causa del fin. ${ }^{5}$

Tras esta aclaración, el Angélico prepara la división interna del objeto de la filosofía moral. Para ello tiene en cuenta que la actividad humana propiamente dicha tiene que ver no sólo con el hombre en cuanto individuo, sino también como miembro de una sociedad:

El hombre es un animal social por naturaleza, ya que necesita de muchas cosas para poder vivir y que él solo no puede proporcionarse. Así que el hombre es naturalmente parte de una multitud, que le ayuda a vivir bien. Y necesita de esta ayuda con vistas a dos objetivos: 1) En orden a las cosas necesarias para la vida y sin las cuales la vida presente no puede lograrse. Esta ayuda le viene al hombre de la multitud doméstica, de la que forma parte. En efecto, todo hombre recibe de sus progenitores tanto la procreación como la crianza y el aprendizaje. De modo semejante, cada uno de los miembros de la familia doméstica ayuda a los demás en lo necesario para la vida. 2) En orden a una vida perfecta, e.d., para que el hombre no sólo viva, sino que viva bien, teniendo todo lo que le basta para vivir. De este modo le ayuda al hombre la multitud civil, de la que forma parte, y no sólo en cuanto a lo corporal[...], sino también en cuanto a lo moral, a saber, en cuanto que los jóvenes insolentes, que no pueden ser corregidos con las amonestaciones paternas, se ven coaccionados por el miedo al castigo que puede infligirles el poder público. ${ }^{6}$

Esta consideración del hombre como parte de un «todo» podría llevar a pensar que la moral individual o monástica no tiene objeto. Para obviar este error, Tomás nos sale al paso distinguiendo dos clases de «todo», según la conexión existente entre sus partes:

«Este todo que es la multitud civil o la familia doméstica tiene sólo una unidad de orden, según la cual algo no es uno sin más. En este caso la parte puede tener una operación, que no es del todo [...]. No obstante, el todo puede tener una operación que no es propia de alguna de sus partes, sino del todo como tal[...]. Pero hay todos que tienen una unidad no sólo de orden, sino por composición o por coligación e incluso por continuidad; y según esta unidad, algo es uno absolutamente. En este caso no hay una operación de las partes que no sea del todo[...], y una misma ciencia se ocupa del todo y de sus partes. Pero no ocurre lo mismo cuando el todo posee sólo una unidad de orden». ${ }^{7}$

De ahí deduce el Aquinate las tres partes tradicionales de la moral: Monástica, económica y política.

\section{LA INTRODUCCIÓN DE PEDRO DE OSMA}

Como advertí ya al comienzo de este trabajo, Pedro de Osma sigue el iter de las introducciones de los comentarios clásicos:

$5 S T, 3$.

$6 S T, 4$.

7 ST, 5. 
1. TITULO: Establece la identidad semántica entre «Liber Ethicorum» y «Líber de moribus», dada la equivalencia del término griego «ethos» con el latino «mos».

2. GENERO: La moral se subordina como especie a su género, que es la «ciencia civil». En efecto, el Osmense divide la ciencia civil en moral y legal. La moral se caracteriza por su universalidad y permanencia, siendo estudiada por Aristóteles en los libros económicos y políticos, y, sobre todo, en éstos de la ética: La legal es «quodam modo infinita», pues cada ciudad se rige por sus propias leyes, dependiendo de su situación y de la índole de sus gentes.

3. MATERIA: Aduciendo un texto de la Retórica de Cicerón, el autor define qué se entiende por la materia de una ciencia:

Es materia de una ciencia, aquélla de que trata cada arte y la facultad procurada por el arte. ${ }^{8}$

Aplicado al caso presente:

Dado que toda ciencia civil versa sobre las perturbaciones del ánimo, especialmente sobre el placer y el dolor [...], tal será la materia de esta ciencia. Pues del mismo modo que decimos que la materia de la medicina son las enfermedades y heridas del cuerpo, asi se dice que la materia de la ciencia civil son las perturbaciones del ánimo a las que, no sin razón, muchos llaman enfermedades del ánimo. No por ello pretendemos negar que la ciencia civil se ocupe también de lo exterior, sino que mayormente trata de lo interior. Pues si bien es verdad que a veces se desvía hacia lo exterior, es para ordenarlo hacia lo interior. Se entiende, pues, que la ciencia civil sea activa, no factiva, pues trata de las perturbaciones del ánimo que son de orden operativo, no productivo. Las producciones, según el Filósofo en IX de la Metafisica, son operaciones transeúntes a una materia exterior; mientras que las acciones tienen un término interior $[\ldots] .^{9}$

4. FIN: El obrar bien y el vivir rectamente y de acuerdo con la razón. Y dado que la bondad humana no puede ser externa, ni relativa a los bienes corporales, sino tan sólo al bien del ánimo, de ahí que esta ciencia intente regular al hombre interior, es decir, a la razón práctica y a todo el apetito que obedece a la razón.. Se sigue, pues, que nos hallamos ante una ciencia práctica, y no especulativa. ${ }^{10}$

5. PARTES: Se da la división de la «Ética a Nicómaco», sintetizando en un rótulo el contenido de cada libro:

I: De la quiddidad o definición de la felicidad.

II: De la virtud en general y del término medio, «mediocritas».

III: De algunos principios de las virtudes, a saber, de lo voluntario e involuntario, de la elección y de la voluntad; y de la fortaleza y de la templanza en particular. 
IV: De ocho virtudes, a saber, de la liberalidad, de la magnificencia, de la magnanimidad y de la virtud que es respecto de ella como la liberalidad respecto de la magnificencia; de la mansedumbre, de la veracidad y de la virtud que se asemeja a la amistad, del buen gusto o convivencia («de urbanitate sive commitate»); y, por último, del pudor, que de algún modo merece alabanza.

$\mathrm{V}$ : De la justicia y sus partes.

VI: De las virtudes intelectivas y sobre todo de la prudencia.

VII: De la continencia, de la perseverancia y de la molicie, del heroísmo y de la grandeza de ánimo; también acerca del placer corporal.

VIII: De la amistad y de sus especies.

IX: De las propiedades de la amistad.

X: Del placer intelectual y cuál es la virtud cuya operación constituye la felicidad del hombre.

6. CLASES DE CIENCIAS: Pedro de Osma considera que tanto el intelecto especulativo como el práctico son «cognitivos», aunque de modo diferente: El especulativo busca sólo su propia perfección, mientras que el práctico pretende la perfección de la voluntad o apetito. Es decir, que el intelecto se hace práctico por extensión, o sea, por el hecho de intentar dirigir al apetito.

Según esto, tanto la ciencia especulativa como la práctica son hábitos especulativos. La primera busca sólo la perfección del intelecto en que reside; la segunda persigue la perfección no tanto del intelecto en que reside, sino la del apetito por causa del cual se ha originado. De modo que la diferencia de ambas ciencias se debe al fin que persiguen. Aquí Pedro de Osma se remite a III «De anima» y a II de la Metafísica. ${ }^{11}$

Resumiendo:

La ciencia especulativa es sólo por el saber, que es el acto del intelecto; y la práctica por causa del obrar y actuar del apetito y de las demás potencias, que son movidas por el apetito y le obedecen. ${ }^{12}$

De todo lo dicho se sigue la siguiente conclụsión:

En primer lugar, únicamente la especulativa se llama propiamente ciencia y filosofía, mientras que la práctica se denomina con mayor propiedad potencia antes que ciencia o filosofía. Pues la ciencia y la filosofía no se refieren tanto a los principios del obrar cuanto a los del conocimiento. En cambio, el nombre de potencia hace referencia a un principio del obrar más que del conocimiento. Así que esta es la índole de la ciencia práctica. Si las cosas han de ser denominadas por el fin, dado que el conocimiento práctico se refiere a la operación, habrá de llamarse ciencia operativa más que cognitiva, siendo así más una potencia que una ciencia. Esta es, al parecer, la causa de que el Filósofo en VI y XI de la Metafísica no enumere a la práctica entre las partes de la filosofía, sino que la dividiese sólo en tres: física, matemática y teología. Ahora biẹn, como el mismo Aristóteles demuestra en esos lugares, estas son las partes de la ciencia especulativa. Por lo tanto, si la ciencia y la filosofía se toman en sentido estricto, no habrá más filosofías que estas tres; pero si el nombre de cien-

11 De anima, III, 10, 433 a, p. 13 ss. Metaf. II, 1, 993b, pp. $20-21$.

$12 J L$, p. 83. 
cia y filosofía se entiende de un modo más amplio, entonces no solamente se llamarán ciencias y filosofías las especulativas, sino también todas las prácticas; y de este modo, y en concordancia con Aristóteles, emplearemos a continuación el nombre de ciencia y filosofía». ${ }^{13}$

Dicho de modo resumido: filosofía en sentido estricto es solamente la física, la matemática y la teología; pero en un sentido amplio lo son también las ciencias prácticas, que no son menos cognitivas que las teóricas, sino que se denominan así por el fin que persiguen: dirigir el apetito y demás facultades activas.

\section{PARTES DE LA FILOSOFíA:}

1. Especulativa $\left\{\begin{array}{l}\text { Física } \\ \text { Matemática } \\ \text { Teología (Metafisica o Transfísica) }\end{array}\right.$

2. Práctica $\begin{cases}\begin{array}{l}\text { Quaestuariae } \\ \text { (De factibilibus) }\end{array} & \left\{\begin{array}{l}\text { pure naturales } \\ \text { partim nat. et partim artif. } \\ \text { pure artificiales }\end{array}\right. \\ \begin{array}{l}\text { Civilis } \\ \text { (De agibilibus) }\end{array} & \left\{\begin{array}{l}\text { Moralis } \\ \text { Legalis }\end{array}\right.\end{cases}$

Acerca de la Teología advierte Pedro de Osma que se trata de la considerada por Aristóteles en su Metafísica. Y sobre el nombre aclara que Aristóteles la llamó «Teología» y que «los nuestros» le cambiaron el nombre por Transfísica o Metafísica. Respecto de las ciencias productivas («factibiles»), dice que es más correcto llamarlas «quaestuariae», que podríamos traducir por ciencias útiles o productivas o adquisitivas. En efecto, como el mismo autor explica, se trata de aquellas ciencias «que han inventado los hombres para adquirir las cosas necesarias para la vida». Y da una lista tomada del libro I de la política; ${ }^{14}$ agricultura, pastoril, venatoria, piscatoria, metálica, carpintería, mercantil, monetaria y fabril. Esta última contendría múltiples especies: frenatoria, sillería, edificativa, embutiduría, batanería, panadería y, en general, tódas las ciencias artesanales de la ciudad.

Ahora bien, todas éstas y las contenidas bajo ellas serían, según el Filósofo, artes productivas «quaestuariae», serviles, ínfimas y viles. Sin embargo, dentro de su género hay rangos, o sea, que unas son más excelentes que otras. Están las «puramente naturales», como la agricultura, el pastoreo, la caza, la pesca; y de entre ellas sobresale con mucho, según el Filósofo, la agricultura. Otras son en parte naturales y en parte artificiales, como la metalurgia y la carpintería. Lógicamente, las puramente naturales son superiores a éstas. Vienen luego las "puramente artificiales», todas inferiores a las naturales, siendo las ínfimas las artes monetarias.

Por lo que se refiere a las ciencias activas («agibiles»), Pedro de Osma opina que es más correcto llamarlas «civiles». La «Ética a Nicómaco» trata «de moribus» y, consecuentemente, pertenece a la Filosofía Moral. Pero se plantea una cuestión acerca de la Política y de la Economía. Para nuestro autor la dificultad proviene tanto del asunto mismo como de lo dicho por el propio Aristóteles: 
Cuando ojeamos esos libros, comprobamos que ni tratan totalmente de las leyes, ni de las costumbres. Además, vemos que Aristóteles las coloca a veces en la moral y a veces en la legal. Al final de la Ética dice abiertamente que después de haber tratado en ella de las costumbres, tratará de las leyes a continuación en la Política. Asimismo, dice en la Política que trató de algunas cosas en el libro de las costumbres; de donde resultaría que el libro de la Política no trataría de las costumbres. Y, sin embargo, en no pocos lugares del mismo libro remite ciertas cosas a los legisladores y gobernantes de las ciudades y a la ciencia que trata de las leyes, de tal manera que ha dicho frecuentemente que ciertas cosas no pertenecen a este libro, sino a la ciencia legal. De donde se sigue, al parecer, que el tal libro no se contiene en la legal, sino más bien en la moral. ${ }^{15}$

Ahora bien, para Pedro de Osma esta controversia se ha originado a partir de un equívoco acerca de los nombres «legal» $\mathrm{y}$ «moral»:

En efecto, la legal y la moral se entienden de dos maneras: de un modo se llama legal aquella en que se trata del orden y de las leyes de alguna nación o ciudad, y en este sentido la Política de Aristóteles no es legal; de otro modo, puede llamarse legal aquella en que se enseña de una manera general y absoluta la doctrina acerca de la república y sus especies, asi como de los principios de la legislación, de forma que puedan ser aplicados a todas las naciones; y en este sentido, sin duda que la Política es legal, no moral. Así, el propio Aristóteles denomina a veces legal a la que trata de las leyes de una nación determinada, pero otras veces a la que considera de modo universal los principios de la legislación y el orden civil. No hay, pues, contradicción alguna en sus afirmaciones, si una veces usa el nombre en un sentido y otras en otro. Sin embargo, entre nosotros se ha hecho usual llamar filosofía moral a toda la ciencia aristotélica que trata de las acciones. y, ciertamente, todas las especulativas y las civiles operativas no son serviles, sino nobles y libres. Sólo las productivas son colocadas por el Filósofo en su Política entre las serviles, y las demás entre las nobles. ${ }^{16}$

Aclarada esta cuestión y concluyendo su introducción, nuestro autor plantea el problema de en qué parte de la filosofía colocar la ciencia militar, la bélica y todo arte ejercitativo, e incluso la gramática, la retórica y la dialéctica. Ahora bien, acerca de las primeras Pedro de Osma no tiene dudas de que, según el Filósofo, deben incluirse en la ciencia civil. Pero en cuanto a las ciencias del «trivium» comprueba que los pareceres se multiplican. Ocurre incluso que algunos, dándoselas de inteligentes, demuestran no entender nada. Más he aquí la posición del autor en sus propios términos:

A mi me parece que la dialéctica pertenece a la filosofía especulativa, mientras que la retórica y la gramática pertenecen a la filosofía civil. En efecto, parece que es propio del filósofo no sólo conocer la verdad y demostrarla, sino también poseer el modo de demostrarla; y de esta manera nace y brota de la filosofía misma. Pero la cuestión de la gramática y de la retórica es distinta. En efecto, el hablar con elegancia y bellamente, perteneciendo lo primero a la gramática y lo segundo a la retórica, atañe no poco a las costumbres de los hombres. ${ }^{17}$

Y así termina el discurso introductorio del profesor salmantino a su comentario de la «Ética a Nicómaco».

$\begin{array}{ll}15 & 15 J L, p .84 \\ 16 & J L, \text { p. } 85 . \\ 17 & J L, \text { p. } 85 .\end{array}$




\section{COTEJO ENTRE AMBAS INTRODUCCIONES}

Salta a la vista la diversidad de estructura y método en ambas introducciones. Es evidente que en los dos casos hay una preocupación por ubicar la materia de la «Ética a Nicómaco» en el organigrama de la filosofía y que esto lleva a ambos autores a presentar una división de la misma. Ahora bien, en Tomás esta división es cuatripartita, mientras que la de Pedro de Osma es bimembre. Mientras el Aquinate, atendiendo al «orden» como objeto de consideración de la filosofía, divide a ésta en natural, racional, moral y artificial; el Osmense, teniendo en cuenta la finalidad del conocimiento, distingue entre filosofía especulativa y filosofía práctica. Además, el de Aquino no presenta la división tripartita de la filosofía especulativa, que sí reproduce el de Osma. Tampoco enumera el primero las diversas artes, cosa que hace Pedro de Osma agrupándolas bajo los tres epígrafes: naturales, artificiales y mixtas. Es también peculiar del profesor salmantino considerar como filosofía o ciencia práctica tanto a las artes productivas como a las ciencias civiles, dividiéndose éstas a su vez en filosofía moral y legal.

No encontramos, por supuesto en el Osmense una consideración del «ordo» objeto de la «ratio» y de sus clases, tal como hace el Aquinate al inicio de su discurso. Tampoco hallamos sus reflexiones acerca del «todo» y de sus partes; sobre las clases de «todo» y las operaciones que corresponden a éste y a sus partes, para salvar el carácter autónomo del individuo, sin excluir el obrar de la comunidad en cuanto tal; ni las precisiones sobre el significado del término «operationes humanae» como objeto de la moral.

Por otra parte, Tomás hace una exposición serena y pacífica, y no tan aporética y polémica como la de Pedro de Osma en algunos momentos. Por ejemplo, al afrontar el equívoco sobre el nombre de la filosofía política y la cuestión de si ésta ha de ser considerada ciencia moral o legal; o la cuestión exegética acerca del sentir de Aristóteles; 0 la conclusiva sobre las artes militares y las del «trivium». También es exclusiva del Osmense la consideración de la filosofía activa o civil en analogía con la medicina; ésta se ocupa de las enfermedades del cuerpo, aquélla de las del alma.

Resulta también llamativa la advertencia de que la filosofía práctica es denominada así no porque no sea una ciencia, y como tal teórica y cognitiva, sino por extensión o por la finalidad, que es la actividad recta y ordenada. Tampoco encontramos en Tomás la distinción entre filosofía en sentido estricto y en sentido amplio, que el Osmense cree fundada en los propios textos de Aristóteles.

En resumen, tanto desde el punto de vista estructural como del contenido, los intereses de Pedro de Osma parecen discurrir por unos derroteros diversos a los del Angélico. En conjunto podríamos caracterizar la introducción del primero como más explícita o interesadamente aristotélica. En efecto, Santo Tomás sólo cita de modo expreso al Filósofo dos veces, en ambos casos la Metafísica (libros I y XII respectivamente), dentro del párrafo inicial sobre el orden: «sapientis est ordinare»; «ordo partium exercitus ad invicem est propter ordinem totius exercitus ad ducem». En cambio, Pedro de Osma apela a Aristóteles constantemente y en todos los apartados: En el primero sobre el titulo de la obra, por supuesto; en el segundo sobre el género apela reiteradamente a él; en el tercero sobre la materia, aunque comienza con una cita de la Retórica de Cicerón, termina con una referencia explícita al libro IX de la Metafisica, a propósito de la distinción entre operaciones inmanentes y transeúntes; en el apartado cuarto sobre el fin menciona dos veces al Filósofo; en el quinto presenta la división de la obra en sus diez libros, sintetizando su contenido; en el sexto, con motivo de la distinción entre ciencia especulativa y práctica, cita el III «De anima» y el II de la 
Metafísica para justificar la diferencia entre entendimiento y ciencia especulativos y prácticos por el fin que persiguen.

Dentro de este mismo apartado explica en qué sentido hace Aristóteles una división tripartita de la filosofía en los libros VI y XII de la Metafisica, y concluye advirtiendo que en adelante, cuando se refiera a la filosofía y sus partes, pensará en la filosofía en un sentido amplio, de acuerdo también en ello con Aristóteles; y en el apartado séptimo y último sobre las partes de la filosofía ,invoca de nuevo la división tripartita de la filosofía especulativa establecida por el Filósofo en su Metafisica, asi como la denominación de «teología» dada por él a la más importante de las tres; toma del libro I de la Política la lista de ciencias «quaestuariae»; afronta el problema hermenéutico de la denominación de la filosoff́a moral o legal para la Política y la Económica en los textos de Aristóteles; y, finalmente, cree acorde con el sentir del Estagirita la inclusión de las artes militares en la ciencia civil.

Podríamos tal vez arriesgar la hipótesis de que el planteamiento e interés de Tomás es más especulativo y el del Osmense más exegético y práctico. La introducción del Aquinate, insisto, está dominada del principio al fin por el concepto de «ordo»:

Es propio del sabio el «ordinare»; lo característico de la «ratio» es conocer el «ordo». El orden es de dos clases: de las partes entre sí y de las cosas respecto del fin. Hay cuatro clases de «ordo» y, así, surgen cuatro tipos de ciencias. La moral se ocupa de los actos humanos voluntarios «secundum ordinem rationis». El todo familiar y social tiene «solam unitatem ordinis»y, por tanto, sus partes pueden tener una operación propia y distinta de las del todo; etc.

A Pedro de Osma, en cambio, le interesa más bien determinar el significado de la palabra «ética» en el titulo de la obra; el género al que ésta pertenece; la materia de que trata y el fin que se propone, todo ello según el sentir de Aristóteles; le interesa establecer si la moral es un saber teórico o práctico, y en qué sentido es lo uno y lo otro según el Filósofo; le preocupa determinar si Aristóteles considera a la Política como una filosofía moral o legal, y en qué sentido es ambas cosas; llama ciencia civil tanto a la moral como a la legal y su exposición es en conjunto dialéctica y didáctica a un tiempo.

Todo parece indicar que en Pedro de Osma hay una voluntad explícita de ser especialmente fiel a la letra y al sentir de Aristóteles ya desde los prolegómenos de su comentario, y que su rechazo de la traducción empleada por Tomás, le lleva a seguir su propio derrotero exegético y doctrinal. Será interesante proseguir la confrontación a lo largo del comentario del texto aristotélico.

Juan Acosta Rodríguez

Departamento de Filosofía y Lógica

y Filosofía de la Ciencia

Campus «Miguel de Unamuno»

Edificio F.E.S.

Universidad de Salamanca 